\title{
THE ROLE OF NUTRITION IN THE DEVELOPMENT OF ATHLETES' ABILITY
}

\author{
Ermatova S.U.
}

The Institute Of Retraining And Advanced Training Of Specialists In Physical Culture And Sports, Uzbekistan

\section{ABSTRACT}

This article discusses the nutritional components necessary for the athlete, the main components of food, the role of protein in the biochemical functions of the athlete, the role of nutrition in energy supply of muscle activity, the diet of athletes in basic training, opinions on nutritional characteristics in the pre-competition stage.

KEYWORDS:- Nutrition, metabolism, energy, proteins, amino acids, vitamins, minerals.

\section{INTRODUCTION}

Nutrition is a key factor in ensuring the growth and development of the athlete's body, increasing his ability to work and adapting to the environment. Nutrition has a big impact on an athlete's performance.

The question arises as to what should be the basis for determining the quantity, composition and quality of food in the development of a rational diet for athletes. The answer is to compare an athlete's need for nutrients with the chemical composition of the food.

The basic ingredients of food for 16-year-olds and older include 10 amino acids, 14 minerals and 13 vitamins. However, these figures are not final and may change with the accumulation of theoretical and practical data in the field of rational nutrition.

Rationalizing the nutrition of athletes requires addressing issues such as organizing it at different stages of the annual training and competition cycle. The purpose of creating specific rations, menus, or developing a specific diet is, first and foremost, to achieve maximum consistency between the possible effects of the diet on the athlete's body and the tasks set by the coach for that period. If there is specific biochemical and physiological data on the metabolism and condition of the athlete's body, the climatic and geographical conditions of training and competition, when performing nervous and mental stress, physical activity of varying duration and intensity, anthropometric and other individual characteristics.

Given the importance of proteins in living nature, as well as the fact that proteins make up half of the mass of living organisms and have a number of remarkable properties, understanding the structure and function of proteins, is the basis for solving important nutritional problems. Proteins perform a wide variety of functions that are unique to an athlete's body. In 1938, the Swedish chemist I.Ya. Berselius separated nitrogen-fixing 
CURRENT RESEARCH JOURNAL OF PEDAGOGICS 2(10): 86-90,

October 2021 DOI: https://doi.org/10.37547/pedagogics-crjp-02-10-16

ISSN 2767-3278

(C)2021 Master Journals

Crossref doi) $\mathrm{g}^{\prime}$ Google

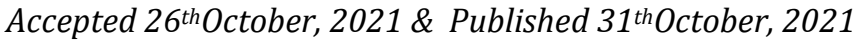

organic compounds from plant and animal tissues and called them proteins (Greek protos primary, meaning important). In the modern medical literature, high-molecular compounds that store nitrogen are called proteins.

Protein performs the following biochemical functions in the human body:

1. Structural function - all tissues, cells and organelles are made up of protein. Here, fibrils play an important role in proteins (collagen, keratin, elastin, etc.).

2. Catalytic function - biocatalysts in the body enzymes have a protein nature and control the occurrence of all biochemical reactions, that is, allow the rate of reactions to proceed and be controlled in a certain order.

3. Energy function - proteins are broken down in the gastrointestinal tract and absorbed in the form of simple amino acids. Some of the amino acids are oxidized to produce energy.

4. Transportation function. Proteins are highly soluble in water and blood, and form a complex with insoluble substances in water and blood, ensuring their solubility and transport. For example, plasma protein albumin transports fatty acids, lipids, and other proteins such as iron, copper, vitamins, and hormones to target organs.

5. Reduction function - acid, myosin, troponins, which are part of muscle proteins, have the ability to contract. These proteins enter the muscles and participate in mechanical work. The contractile function is also characteristic of cytoskeletal proteins, which provide the processes of cell life (mitosis, chromosome separation).

6. Protection function. Foreign proteins, viruses, and bacterial toxins that enter the body are considered antigens, and protective proteins against them form antibodies that bind to the antigens and neutralize them. Plasma fibrinogen and thrombin proteins are involved in blood clotting, preventing the body from losing blood in the event of various injuries.

7. Base function. It is made up of skin, bones, nails, hair, joints, and proteins, and acts as a base for the Athlete's body.

8. Management function. Some control substances, hormones, are proteins. For example, the hormone insulin, a highly biologically active substance, is involved in the regulation of metabolism.

9. Hereditary function. The chromosomes that store genetic information are complex proteins made up of nucleoproteins

One of the most important rules for determining the anabolic effect of food protein is the ratio of essential amino acids in it. The nutritional value of proteins also depends on the enzymes of the gastrointestinal tract, which are present in large quantities and accelerate the breakdown of all proteins into free amino acids.

The nutritional properties of proteins are usually determined by chemical and biological values. To do this, the protein is completely hydrolyzed, its amino acid content is determined and compared with a standard protein. The analysis determines the chemical value of this protein. The amino acids in all proteins differ significantly. Some of them contain a complete set of amino acids in optimal proportions.

In the cells of the athlete's organs and tissues, many enzymatic reactions occur, combined with the general concept of metabolism. Metabolic processes are highly coordinated systems of chemical reactions carried out by interrelated enzyme systems that make up individual metabolic cycles and years. Although metabolism involves hundreds of different enzymatic reactions, the basic metabolic pathways and 


\section{Crossref doi) 81 Google}

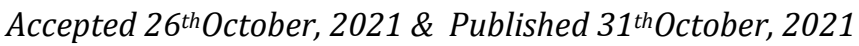

cycles are very limited and essentially the same in all living organisms. The athlete's body can be divided into four main metabolic functions that ensure the integrity of various aspects of life. Metabolism first provides the body with chemical energy generated during the breakdown of nutrients; second, it converts nutrients into compounds of molecular weight, which are then used in biosynthetic processes; third, it synthesizes proteins, nucleic acids, lipids, polysaccharides, glycoproteins, proteoglycans, and other cells; and finally, it creates the conditions necessary for the synthesis and breakdown of biological molecules that enable a particular cellular function to be performed.

Proper nutrition, which is one of the most important and necessary processes in an athlete's life, is a comprehensive concept, and its study and analysis pays close attention to the principles of rational nutrition. Among them is the principle of order or diet.

It is known that protein, fat and carbohydrates from food components are not absorbed directly into the blood. They must first be broken down into the smallest units in the digestive tract, the monomers. This process is performed by enzymes in the sap that are secreted by special glands in the digestive tract. Importantly, the breakdown of nutrients is not a flat one, but goes from front to back. For example, if one enzyme is involved in the breakdown of starch to sugar, another enzyme is involved in the conversion of sugar into glucose. The same proteins and fats are broken down gradually. Decomposing enzymes, on the other hand, are produced by special cells in separate amounts at each meal, for example, the enzymes released during breakfast are not involved in digesting lunch, but new enzymes are produced for it. Dinner enzymes are also synthesized independently. In addition, special transport molecules are needed for nutrients to be converted into simple molecules (i.e., monomers) from the intestinal wall into the bloodstream. If they are not produced in time, nutrients will not get into the bloodstream. It turns out that the synthesis and activity of these enzyme molecules and carrier molecules are subject to diurnal biorhythms.

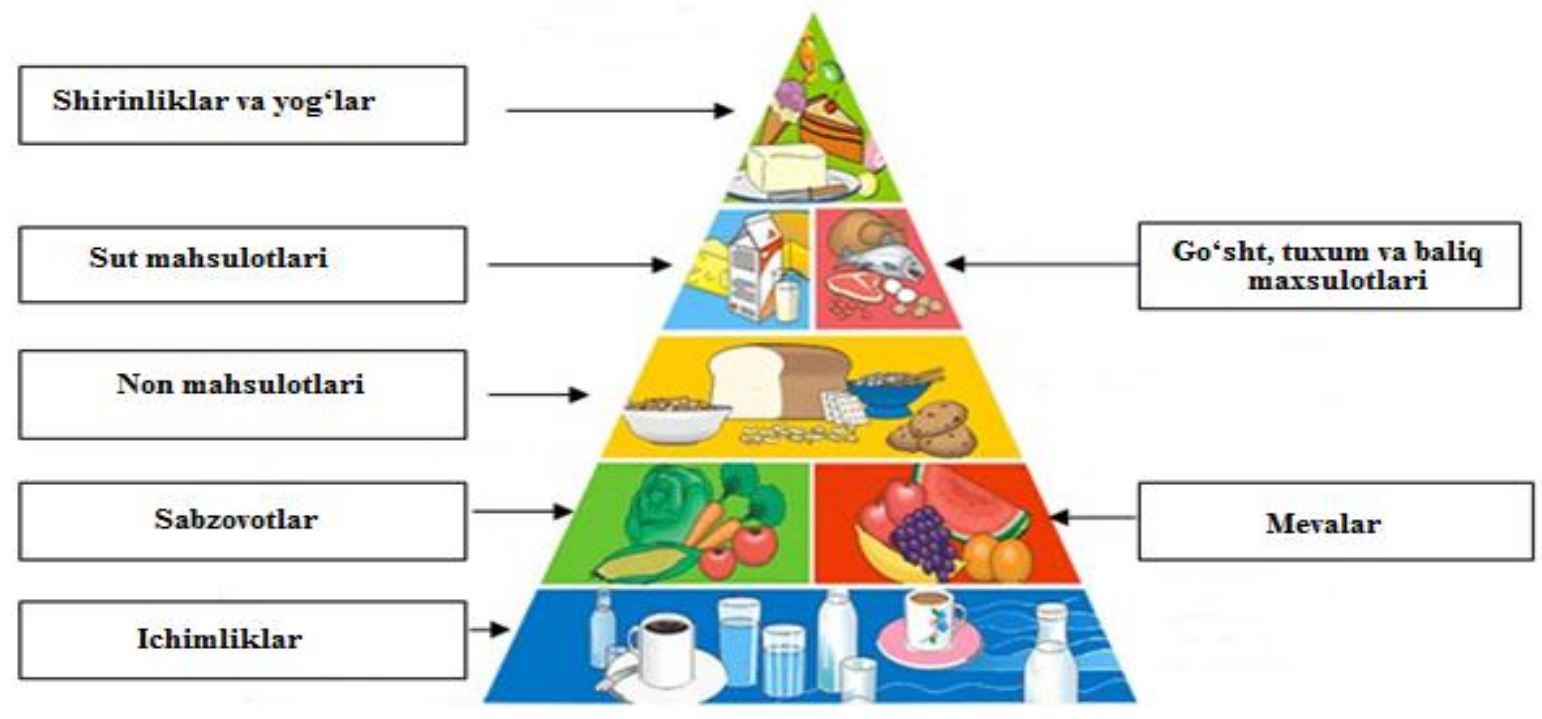


CURRENT RESEARCH JOURNAL OF PEDAGOGICS 2(10): 86-90,

October 2021 DOI: https://doi.org/10.37547/pedagogics-crjp-02-10-16

ISSN 2767-3278

(C)2021 Master Journals

\section{Crossref doi) 81 Google}

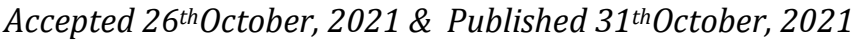

\section{The food pyramid}

The pyramid has been recommended by the World Health Organization as the basis for a healthy diet. The food pyramid consists of five layers, the base of which is the amount of liquid consumed, the second layer is fresh fruits and vegetables, and the third layer is potatoes and bread. The top layer consists of meat, milk, eggs and fish products, and the top layer consists of sugar, sweets, salt and fats.

As mentioned above, the adaptation of the nature of the diet to the metabolic changes that occur as a result of muscle activity largely determines the development of processes in which the athlete's body adapts to exercise and competition loads. Basic principles of nutrition for athletes:

1. Provide the body with the necessary energy to perform its physical activity.

2. Maintain a balanced diet according to the intensity of certain sports and physical activity, including the distribution of the energy value of the main nutrients, which varies depending on the period of preparation for the competition.

3. Immediate selection of appropriate forms of nutrition (food, nutrients and their compounds) during intense and prolonged physical activity, preparation for the competition, the competition itself and subsequent recovery.

4. The use of nutrients to activate and regulate intracellular metabolic processes in various organs and tissues.

5. To create the necessary metabolic background for the biosynthesis and implementation of hormonal effects using food, hormones that regulate the main metabolic reactions (catecholamines, prostaglandins, corticosteroids, cyclic nucleotides, etc.).
6. Extensive use of a variety of foods and their use in a variety of cooking methods to provide the body with all the necessary nutrients in moderation.

7. Include biologically complete and easily digestible foods and foods that do not stress the digestive tract.

8. The use of nutritional factors increases muscle building speed and strength, as well as regulating body weight according to the athlete's weight category.

9. Individualization of nutrition according to the anthropometric, physiological and metabolic characteristics of the athlete, the state of his digestive system, personal tastes and habits.

For many years, these principles of balanced diet have been widely used in the organization of centralized training of athletes in different climatic and geographical zones.

Habit for a particular athlete or group of athletes, maintaining a regimen and diet is very important in achieving a high level of training. To do this, it is important not to introduce new foods, especially special instructions, in the precompetition phase. In such cases, the "excitement" of any metabolism can change the established balance and lead to a decrease in sports form.

In addition, there are a number of consistent problems in the nutrition of athletes that need to be taken into account at different stages of preparation for competitions and on competition days.

Basic requirements for diet and regimen:

1. It is not necessary to get fresh food at least a week before the competition. All foods, especially HBVP (high biological value products), should be pre-tested during training or pre-competition. This 
CURRENT RESEARCH JOURNAL OF PEDAGOGICS 2(10): 86-90,

October 2021 DOI: https://doi.org/10.37547/pedagogics-crjp-02-10-16

ISSN 2767-3278

(C)2021 Master Journals

Crossref doi) $\mathrm{g}^{\prime}$ Google

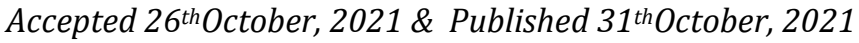

requirement applies not only to the products themselves, but also to the way they are received. Athletes need to know in advance what foods should be included in the diet and when they should be consumed. This is necessary to maintain and support a high level of athletic performance.

2. It is important to avoid overeating during meals. It is better to eat food often, sparingly and easily digested.

3. A normal or high level of glycogen in the muscles and liver is a guarantee of readiness for competitions. This can be achieved by reducing the amount and intensity of training or increasing the amount of carbohydrates a week before the competition. Both processes are possible.

4. It is necessary to create the glycogen reserves necessary for competitive work by increasing the content of carbohydrates in the diet and reducing physical activity. However, we must not forget that this can increase body weight. For example, if the glycogen reserves in the body are doubled, an increase in body weight of $1600-1800 \mathrm{~g}$ is observed with an amount of 30-35 kg of muscle mass. This $1 \mathrm{~g}$ of glycogen "binds" $3 \mathrm{~g}$ of water to the muscles.

5. It is required to eat light food at night before the race. It's best not to try to eat for the last few minutes. You need to gradually increase your carbohydrate intake during the week before the race.

In short, the health and well-being of our athletes depends on the minerals in the food they eat. The use of a variety of foods in an athlete's daily diet can help improve athletic performance.
1. Decree of the President of the Republic of Uzbekistan dated October 30, 2020 No. PF6099 "On measures to develop mass sports and the introduction of a healthy lifestyle in the lives of every citizen."

2. Borisova 0.0. Nutrition for athletes. Soviet sport, 2007. - 132s

3. Karimov Sh.I. Healthy eating is a measure of health. - Tashkent. 2015.

4. Kuchkarova L.S., Qurbonov Sh.Q. Digestion and nutritional physiology. - Tashkent. 2013.

5. Pshendin P.I. Rational nutrition for athletes. - M .: 2005.

6. Sobirova R.A., Abrorov O.A .. Inoyatova F.X, Aripov A.N. Biological chemistry. Tashkent. New Age Generation, 2006.

7. Toychiboyev M.U. Sports biochemistry. Tashkent. Tafakkur-bostoni, 2012.

8. Qurbonov Sh.Q. Food culture. - Tashkent. Spirituality, 2005

9. Qurbonov Sh.Q., Yuldashev R., Qurbonov A.Sh. Proper nutrition is the key to good health. - Against. 2014.

\section{REFERENCES}

